\title{
Clinical and Sociodemographic Associates of Remission from Positive Symptoms in Schizophrenia
}

\author{
AK Jana
}

\begin{abstract}
Objectives: To determine factors associated with remission from positive symptoms in Indian patients with schizophrenia.

Methods: We evaluated 151 patients (99 men and 52 women) aged 18 to 65 years who were diagnosed with schizophrenia and followed up for $\geq 6$ months (with a minimum of two evaluations). We assessed psychopathology, the level of best functioning in the past year, premorbid functioning (up to 1 year), daily living skills, medication adherence, adverse effects to medications, the number of stressful events in the 6 months before illness onset, perceived social support, expressed emotion from family, and personal construct of empowerment. Remission from positive symptoms of schizophrenia was defined as simultaneous attainment of a score of $\leq 3$ (mild) for $\geq 6$ months in the following symptoms: delusions, concept disorganisation, hallucinatory behaviour, unusual thought content, mannerisms, and posturing. Patients were categorised as remitted and non-remitted.

Results: Of 151 patients, $81(53.64 \%)$ fulfilled the remission criteria. Compared with non-remitted patients, remitted patients had a shorter duration of untreated psychosis $(\mathrm{t}=-2.29, \mathrm{p}<0.05)$, better premorbid functioning in childhood $(\mathrm{t}=-1.99, \mathrm{p}<0.05)$ and general $(\mathrm{t}=-9.34, \mathrm{p}<0.001)$ subscale, higher medication adherence $(\mathrm{t}=6.91, \mathrm{p}<0.001)$, higher daily living skills $(\mathrm{t}=8.65, \mathrm{p}<0.001)$, better perceived social support $(\mathrm{t}=6.69, \mathrm{p}<0.001)$, higher empowerment $(\mathrm{t}=5.64, \mathrm{p}<0.001)$, and received higher warmth $(\mathrm{t}=1.99, \mathrm{p}<0.05)$ and lower hostility $(\mathrm{t}=-4.00, \mathrm{p}<0.001)$, dissatisfaction $(\mathrm{t}=-6.96$, $\mathrm{p}<0.001)$, and critical comments $(\mathrm{t}=-2.48, \mathrm{p}<0.05)$ from family members. Predictors of remission were duration of untreated psychosis $(B=-0.020, p<0.05)$, daily living skills $(B=2.063, p<0.001)$, perceived social support $(B=0.084, p<0.01)$, and dissatisfaction from family members $(B=-0.621, p$ $<0.01)$.

Conclusions: $53.64 \%$ of patients with schizophrenia achieved remission from positive symptoms. Remission was more likely to occur in patients with shorter duration of untreated psychosis, better daily living skills, higher perceived social support, and less dissatisfaction from family members.
\end{abstract}

Key words: Remission induction; Schizophrenia; Social support

Amlan Kusum Jana, KPC Medical College \& Hospital, Kolkata, India

Address for correspondence: Amlan Kusum Jana, KPC Medical College \& Hospital, Kolkata, India.

Email:amlankjana@gmail.com

Submitted: 18 September 2019; Accepted: 14 August 2020

\section{Introduction}

Schizophrenia used to be considered a chronic condition that eventually leads to a deterioration of clinical and functional status. The core feature of schizophrenia is a downhill course and eventual adverse outcome. DSM III stated that "a complete return to premorbid level of functioning in individuals diagnosed with schizophrenia is so rare as to cast doubt upon the accuracy of the diagnosis". ${ }^{1}$ However, the course of schizophrenia is heterogeneous and not necessarily a downhill one. ${ }^{2}$
Outcome is an ambiguous concept and is defined as the net balance of the clinical and functional descriptors at the endpoint. However, no such endpoint exists in dynamic conditions such as schizophrenia. ${ }^{3}$ There is no single parameter to assess the outcome, along with clinical symptoms, functionality, and social role performance. ${ }^{3}$ Newer parameters have been included in the concept of outcome, and rehabilitation or treatment satisfaction ${ }^{4}$ should also be considered.

The International Pilot Study of Schizophrenia ${ }^{5}$ investigated the nature of the illness using standardised methods and procedures to assess prognosis and illness course. In two Swiss studies of the long-term course of schizophrenia, a considerable proportion of patients achieved better outcome, with significant reduction in symptoms and a fair level of social and occupational functioning. . $^{2,6}$

Predictors of outcome of schizophrenia have been studied $^{7,8}$ and include neurological soft signs ${ }^{9}$ and mental 
resilience. ${ }^{10}$ Concepts of remission ${ }^{11}$ and recovery ${ }^{12}$ have gained popularity, and newer medicines and rehabilitation methods (eg, empowering programme ${ }^{13}$ ) are developed.

The present study aimed to determine factors associated with remission from positive symptoms in Indian patients with schizophrenia. This study is a part of a larger study on outcomes of schizophrenia published previously. ${ }^{14}$

\section{Methods}

This cross-sectional retrospective study was approved by the ethics review board of the Central Institute of Psychiatry, Ranchi, India. Written informed consent was obtained from each patient. We evaluated 151 patients (99 men and 52 women) aged 18 to 65 years who were diagnosed with schizophrenia according to ICD-10-DCR ${ }^{15}$ and were on regular follow-up for $\geq 6$ months (with a minimum of two evaluations). Patients with any comorbid major medical or neurological disorder, mental retardation or any comorbid psychiatric illness were excluded.

Psychopathology was assessed using the Positive and Negative Syndrome Scale (PANSS). ${ }^{16}$ The level of best functioning in the past year was assessed using the Global Assessment of Functioning. ${ }^{17}$ Premorbid functioning (up to 1 year) was assessed using the Cannon-Spoor Premorbid Adjustment Scale after modification (PAS). ${ }^{18}$ Daily living skills were assessed using the informant-rated version of the Independent Living Skills Survey (ILSS). ${ }^{19}$ Medication adherence was assessed using the Drug Attitude Inventory (DAI). ${ }^{20}$ Adverse effects to medications were assessed using the Udvalg for Kliniske Undersogelser ${ }^{21}$ and by interview of the patients. The number of stressful events in the 6 months before illness onset was recorded using the Presumptive Stressful Life Event Scale, ${ }^{22}$ which is an Indian adaptation of Social Readjustment Rating Questionnaire. ${ }^{23}$ Perceived social support was measured using the patient-rated PGI Social Support Questionnaire, ${ }^{24}$ which is based on the Social Support Questionnaire. ${ }^{25}$ Expressed emotion from family was assessed using the Attitude Questionnaire. ${ }^{26}$ Personal construct of empowerment was assessed using the self-report Empowerment Scale ${ }^{27}$ with responses ranging from 1 (strongly agree) to 4 (strongly disagree).

Remission from positive symptoms of schizophrenia was assessed using the operationalised criterion proposed by the Remission in Schizophrenia Working Group. ${ }^{11}$ This requires simultaneous attainment of a score of $\leq 3$ (mild) for $\geq 6$ months in the following symptoms of the PANSS: delusions, concept disorganisation, hallucinatory behaviour, unusual thought content, mannerisms, and posturing. Patients were categorised as remitted and non-remitted.

Data were analysed using SPSS (Windows version 10; IBM Corp, Armonk [NY], US). Normality of data was checked using Shapiro-Wilk test. The remitted and nonremitted groups were compared using the independent $t$ test for continuous variables and the Chi-squared test for categorical variables. Logistic regression was conducted with remission as outcome variable, and predicting variables were entered in the forward conditional method. Predictors included duration of untreated psychosis (DUP), severity of positive and negative symptoms, medication adherence, number of stressful events, expressed emotions, perceived social support, and empowerment. The assumption of lack of autocorrelation was tested with Durbin-Watson test. To identify multicollinearity, variance inflation factor was tested. The assumption of homoscedasticity was checked from the plots of standardised predicted values and standardised residuals. The Nagelkerke R2 was calculated to measure the variance explained by the model.

\section{Results}

Of 151 patients, 81 (53.64\%) fulfilled the remission criteria. Compared with non-remitted patients, remitted patients had a shorter DUP $(\mathrm{t}=-2.29, \mathrm{p}<0.05)$, better premorbid functioning in childhood $(\mathrm{t}=-1.99, \mathrm{p}<0.05)$ and general $(\mathrm{t}=-9.34, \mathrm{p}<0.001)$ subscale in PAS, higher medication adherence in DAI $(\mathrm{t}=6.91, \mathrm{p}<0.001)$, higher daily living skills in ILSS $(\mathrm{t}=8.65, \mathrm{p}<0.001)$, better perceived social support $(\mathrm{t}=6.69, \mathrm{p}<0.001)$, higher empowerment $(\mathrm{t}=5.64$, $\mathrm{p}<0.001)$, and received higher warmth $(\mathrm{t}=1.99, \mathrm{p}<0.05)$ and lower hostility $(\mathrm{t}=-4.00, \mathrm{p}<0.001)$, dissatisfaction $(\mathrm{t}=-6.96, \mathrm{p}<0.001)$, and critical comments $(\mathrm{t}=-2.48$, $\mathrm{p}<0.05)$ from family members (Table 1 ).

Predictors of remission were DUP $(\mathrm{B}=-0.020$, $\operatorname{Exp}(B)=0.980, p<0.05), \operatorname{ILSS}$ score $(B=2.063, \operatorname{Exp}(B)=$ $7.873, \mathrm{p}<0.001)$, perceived social support $(\mathrm{B}=0.084$, $\operatorname{Exp}(B)=1.088, p<0.01)$, and dissatisfaction from family members $(B=-0.621, \operatorname{Exp}(B)=0.538, p<0.01)$ [Table 2]. The model explained $61.8 \%$ of the variance (adjusted $\mathrm{R}^{2}=0.618$ ) in remission.

\section{Discussion}

$53.64 \%$ of the patients fulfilled the remission criteria, which have good sensitivity and specificity. ${ }^{28}$ The symptomatic remission rate has been reported to be $37.5 \%{ }^{29}$ and $91.5 \% .^{30}$ Nonetheless, the proportion of patients showing enduring remission is smaller than that showing symptomatic remission for $\geq 6$ months. ${ }^{30}$ The favourable outcomes of our patients may be because our institute is a renowned institute in India, or because only patients with regular follow-up were included. Generalisation of our findings should be done with caution, as this was a hospital-based study and many patients in the community do not receive any professional help.

Perceived social support and ILSS score positively predicted remission. Social support is believed to be bidirectional and is often determined by personality factors such as self-esteem, sociability, and locus of control. ${ }^{31}$ Two components determine the overall social support: individual's own inner resources and characteristics (physical characteristics, biological predisposition, and cognitive capacity to acquire and organise knowledge of self and others) and individual's external social environments. ${ }^{32}$ 
Table 1. Characteristics of patients

\begin{tabular}{|c|c|c|c|c|}
\hline & Remitted $(\mathbf{n}=\mathbf{8 1})^{*}$ & $\begin{array}{c}\text { Non-remitted } \\
\quad(\mathbf{n}=\mathbf{7 0})^{*}\end{array}$ & $t / \chi^{2}$ & p Value \\
\hline Age, $y$ & $35.12 \pm 10.04$ & $33.62 \pm 9.61$ & 0.93 & 0.354 \\
\hline Years of education & $10.90 \pm 4.63$ & $10.24 \pm 4.20$ & 0.91 & 0.365 \\
\hline Age of onset, y & $27.72 \pm 8.75$ & $25.56 \pm 8.47$ & 1.53 & 0.128 \\
\hline Duration of illness, $y$ & $7.61 \pm 8.47$ & $8.13 \pm 6.15$ & -0.55 & 0.584 \\
\hline Duration of untreated psychosis, $\mathrm{m}$ & $8.84 \pm 15.41$ & $18.00 \pm 32.04$ & $-2.29^{*}$ & 0.024 \\
\hline Duration of hospitalisation, $\mathrm{d}$ & $21.47 \pm 38.03$ & $23.24 \pm 38.96$ & -0.28 & 0.778 \\
\hline Number of hospitalisation & $0.53 \pm 0.84$ & $0.57 \pm 0.73$ & -0.31 & 0.754 \\
\hline Dose of medication in chlorpromazine equivalence & $329.87 \pm 87.83$ & $340 \pm 99.29$ & -0.65 & 0.520 \\
\hline Total duration on medication, $y$ & $6.05 \pm 4.81$ & $5.69 \pm 5.62$ & 0.43 & 0.670 \\
\hline Duration of follow-up, $y$ & $3.01 \pm 3.01$ & $2.89 \pm 3.51$ & 0.20 & 0.839 \\
\hline Number of follow-up & $8.01 \pm 6.40$ & $7.69 \pm 8.51$ & 0.27 & 0.789 \\
\hline Interval of follow-up, y & $0.36 \pm 0.21$ & $0.37 \pm 0.29$ & -0.28 & 0.780 \\
\hline Sex & & & 0.52 & 0.470 \\
\hline Male & $51(62.96)$ & $48(68.57)$ & & \\
\hline Female & $30(37.04)$ & $22(31.43)$ & & \\
\hline Religion & & & 1.39 & 0.238 \\
\hline Hindu & $69(85.18)$ & $64(91.43)$ & & \\
\hline Non-Hindu & $12(14.82)$ & $6(8.57)$ & & \\
\hline Ethnicity & & & 1.74 & 0.187 \\
\hline General & $73(90.12)$ & $67(95.71)$ & & \\
\hline Tribal & $8(9.88)$ & $3(4.29)$ & & \\
\hline Marital status & & & 0.08 & 0.775 \\
\hline Married & $47(58.02)$ & $39(55.71)$ & & \\
\hline Single & $34(41.98)$ & $31(44.29)$ & & \\
\hline Income & & & 3.39 & 0.183 \\
\hline Upper & $3(3.70)$ & $2(2.86)$ & & \\
\hline Middle & $63(77.78)$ & $46(65.71)$ & & \\
\hline Lower & $15(18.52)$ & $22(31.43)$ & & \\
\hline Family type & & & 0.48 & 0.491 \\
\hline Nuclear & $53(65.43)$ & $42(60.00)$ & & \\
\hline Joint & $28(34.57)$ & $28(40.00)$ & & \\
\hline Access to medical care & & & 2.56 & 0.279 \\
\hline Good & $23(28.39)$ & $13(18.57)$ & & \\
\hline Medium & $48(59.26)$ & $44(62.86)$ & & \\
\hline Poor & $10(12.35)$ & $13(18.57)$ & & \\
\hline Residence & & & 1.91 & 0.167 \\
\hline Rural & $36(44.44)$ & $39(55.71)$ & & \\
\hline Urban & $45(55.56)$ & $31(44.29)$ & & \\
\hline Medication route & & & 1.90 & 0.168 \\
\hline Depot & $27(33.33)$ & $31(44.29)$ & & \\
\hline Oral & $54(66.67)$ & $39(55.71)$ & & \\
\hline Medication type & & & 0.97 & 0.616 \\
\hline Typical & $4(4.94)$ & $5(7.14)$ & & \\
\hline Atypical & $36(44.44)$ & $27(38.57)$ & & \\
\hline Both & $41(50.62)$ & $38(54.29)$ & & \\
\hline
\end{tabular}

Data are presented as mean \pm standard deviation or No. (\%) of patients 
Table 1. (cont'd)

\begin{tabular}{|c|c|c|c|c|}
\hline & Remitted $(\mathrm{n}=81)^{*}$ & $\begin{array}{l}\text { Non-remitted } \\
\quad(\mathbf{n}=\mathbf{7 0})^{*}\end{array}$ & $t / \chi^{2}$ & p Value \\
\hline $\begin{array}{l}\text { Occupation } \\
\text { Employed } \\
\text { Unemployed } \\
\text { Student/housewife }\end{array}$ & $\begin{array}{l}20(24.69) \\
15(18.52) \\
46(56.79)\end{array}$ & $\begin{array}{l}14(20.00) \\
21(30.00) \\
35(50.00)\end{array}$ & 2.77 & 0.251 \\
\hline $\begin{array}{l}\text { Response to treatment } \\
\text { Poor } \\
\text { Partial } \\
\text { Good } \\
\end{array}$ & $\begin{array}{l}17(20.99) \\
15(18.52) \\
49(60.49) \\
\end{array}$ & $\begin{array}{l}13(18.57) \\
23(32.86) \\
34(48.57) \\
\end{array}$ & 4.15 & 0.126 \\
\hline Global Assessment of Functioning & $74.94 \pm 0.55$ & $56.93 \pm 6.49$ & 24.89 & $<0.001$ \\
\hline $\begin{array}{l}\text { Modified Premorbid Adjustment Scale } \\
\text { Childhood }(\mathrm{n}=151) \\
\text { Early adolescence }(\mathrm{n}=149) \\
\text { Late adolescence }(\mathrm{n}=136) \\
\text { Adult }(\mathrm{n}=119) \\
\text { General }(\mathrm{n}=151)\end{array}$ & $\begin{array}{l}0.03 \pm 0.04 \\
0.06 \pm 0.04 \\
0.07 \pm 0.04 \\
0.05 \pm 0.08 \\
0.19 \pm 0.08\end{array}$ & $\begin{array}{l}0.05 \pm 0.05 \\
0.07 \pm 0.04 \\
0.08 \pm 0.06 \\
0.07 \pm 0.08 \\
0.38 \pm 0.15\end{array}$ & $\begin{array}{l}-1.99 \\
-1.43 \\
-1.77 \\
-1.46 \\
-9.34 \\
\end{array}$ & $\begin{array}{r}0.048 \\
0.155 \\
0.079 \\
0.148 \\
<0.001 \\
\end{array}$ \\
\hline Udvalg for Kliniske Undersogelser & $4.69 \pm 4.58$ & $5.18 \pm 3.16$ & -0.71 & 0.476 \\
\hline Drug Attitude Inventory & $8.04 \pm 1.73$ & $5.54 \pm 2.66$ & 6.91 & $<0.001$ \\
\hline Independent Living Skills Survey & $3.15 \pm 0.48$ & $2.34 \pm 0.66$ & 8.65 & $<0.001$ \\
\hline No. of stressful events in the 6 months before onset & $1.73 \pm 1.30$ & $2.01 \pm 1.39$ & -1.29 & 0.196 \\
\hline Perceived social support & $54.73 \pm 8.36$ & $44.50 \pm 10.43$ & 6.68 & $<0.001$ \\
\hline $\begin{array}{l}\text { Expressed emotions } \\
\text { Critical comments } \\
\text { Hostility } \\
\text { Dissatisfaction } \\
\text { Emotional overinvolvement } \\
\text { Warmth }\end{array}$ & $\begin{array}{r}5.74 \pm 0.83 \\
6.22 \pm 0.55 \\
8.21 \pm 1.02 \\
11.75 \pm 0.86 \\
8.12 \pm 0.95\end{array}$ & $\begin{array}{r}6.11 \pm 1.01 \\
6.69 \pm 0.86 \\
9.53 \pm 1.30 \\
11.53 \pm 1.20 \\
7.81 \pm 0.95\end{array}$ & $\begin{array}{r}-2.48 \\
-4.00 \\
-6.96 \\
1.33 \\
1.99\end{array}$ & $\begin{array}{r}0.014 \\
<0.001 \\
<0.001 \\
0.184 \\
0.049\end{array}$ \\
\hline Empowerment & $78.21 \pm 9.50$ & $69.04 \pm 10.45$ & 5.64 & $<0.001$ \\
\hline
\end{tabular}

Data are presented as mean \pm standard deviation or No. (\%) of patients

Table 2. Logistic regression analysis for predictors of remission in patients with schizophrenia*

\begin{tabular}{|lcccc|}
\hline Variable & B & $\begin{array}{c}\text { Standard } \\
\text { error }\end{array}$ & $\begin{array}{c}\text { exp } \boldsymbol{b} \text { (95\% confidence } \\
\text { interval) }\end{array}$ & p Value \\
Constant & -4.19 & 2.60 & 0.02 & - \\
\hline Independent Living Skills Survey & 2.06 & 0.44 & $7.87(3.31-18.75)$ & $<0.001$ \\
\hline Perceived Social Support & 0.08 & 0.03 & $1.09(1.03-1.15)$ & $<0.01$ \\
\hline Duration of untreated psychosis & -0.02 & 0.01 & $0.98(0.96-0.99)$ & $<0.05$ \\
\hline Dissatisfaction & -0.62 & 0.20 & $0.54(0.36-0.79)$ & $<0.01$ \\
\hline
\end{tabular}

* $\quad R^{2}=0.618($ Nagelkerke $) ;$ Model $\chi^{2}=59.53, p<0.001$

Symptoms, particularly if severe and long-standing, may produce more lasting deficits on the provision of support by family members. ${ }^{31}$ Schizophrenia is a chronic illness and thus affects social outcome early in the course. Higher social support, better coping and social support seeking ${ }^{33}$ have been shown to improve outcome. Satisfaction with social support positively influences the quality of life in schizophrenia patients. ${ }^{34}$

ILSS measures social, occupational, leisurely functions, and skills for daily living. Adequate heterosexual 
contacts and instrumental competence social adjustment occupational functioning affect outcome. ${ }^{35}$ Social cognition, which is the connecting link between symptomatic improvement and adequate socio-occupational functioning, is increasingly targeted in treatments of schizophrenia. Nowadays, the goal of treatment in schizophrenia is remission and recovery. Achieving adequate sociooccupational functioning is an essential step towards it. Independent functioning at various levels has a bilateral relation with clinical symptoms, as both tend to negatively influence each other.

Dissatisfaction in family members negatively predicted remission. Expressed emotions may be predictive of relapse and re-hospitalisations in schizophrenia patients. Expressed emotions may differentially affect psychosocial functioning and not much clinical functioning. ${ }^{36}$ Expressed emotions, specifically dissatisfaction, are associated with poor socio-occupational functioning in schizophrenia. ${ }^{37}$ The degree and frequency of expressed emotions can change with time, and expressed emotions tend to predict relapse better with long-standing illness. Expressed emotions are a valid prolonged predictor of relapses and rehospitalisations. ${ }^{38}$

DUP predicts remission ${ }^{9,32}$ and a favourable outcome (PANSS score). ${ }^{39}$ A short DUP is associated with better social, occupational, and symptomatic outcome. ${ }^{40}$ A metaanalysis concluded that DUP had a small but consistent correlation with poor general symptomatic outcome, more severe positive and negative symptoms, less likelihood of remission, and poor social functioning and global outcome. ${ }^{41}$ Longer DUP predicts worse clinical, functional, and cognitive outcomes in early-onset psychosis ${ }^{42}$ and predicts social anxiety in schizophrenia, which adversely affects outcome. ${ }^{43}$ DUP is an important parameter in India where health care system struggles to reduce the overall treatment gap in schizophrenia. Despite the presence of other protective factors, DUP alone can adversely impact the outcome of schizophrenia by worsening symptomatic and functional outcome through its influence on social cognition and social anxiety. Thus, early intervention in schizophrenia helps to improve the patient outcome.

Negative symptoms have been reported to be a predictor (negative) of remission in schizophrenia, along with participation in standardised psychological treatment, ${ }^{30}$ favourable early response to treatment, general psychopathological symptoms, and lesser psychotic episodes in the longitudinal course. ${ }^{29}$ However, negative symptoms or general psychopathology symptoms was not a predictor of remission in the present study.

One of the limitations of the present study is the homogeneity of the sample. Patients with comorbid illnesses (eg, obsessive-compulsive disorder, major depression, substance dependence) were excluded; these comorbid illnesses could be important predictors. The study is cross-sectional and retrospective. A study with a baseline assessment followed by prospective evaluations would have identified more predictors. A community-based study could have examined patients who could not reach out to hospitals. Assessment of family dynamics, expressed emotions, housing and living conditions, and social support in patients could have helped determine the real picture of outcomes of schizophrenia in India. Studies of psychosocial and biological parameters among patients in the community with a prospective design are warranted. The number of relapses in the past among patients could not be tracked, which could have been an important predictor.

\section{Conclusion}

$53.64 \%$ of patients with schizophrenia achieved remission from positive symptoms. Remission was more likely to occur in patients with shorter duration of untreated psychosis, better daily living skills, higher perceived social support, and less dissatisfaction from family members.

\section{References}

1. American Psychiatric Association. Diagnostic and Statistical Manual of Mental Disorders. 3rd ed; 1980.

2. Ciompi L. Catamnestic long-term study on the course of life and aging of schizophrenics. Schizophr Bull 1980;6:606-18. Crossref

3. Jablensky A. Course and Outcome of Schizophrenia and Their Prediction. In: Gelder MG, Lopez-Ibor JJ, Andreasen NC, editors. New Oxford Textbook of Psychiatry. 2nd ed. Oxford University Press; 2000: 612-21.

4. Lehman AF. Evaluating outcomes of treatments for persons with psychotic disorders. J Clin Psychiatry 1996;57(Suppl 11):61-7.

5. World Health Organization. The International Pilot Study of Schizophrenia. Vol. 1. 1973.

6. Bleuler M. The Schizophrenic Disorders: Long-Term Patient and Family Studies. Translated by SM Clemens. Yale University Press; 1978.

7. Vaillant GE. The prediction of recovery in schizophrenia. J Nerv Ment Dis 1962;135:534-43. Crossref

8. Stephens JH, Astrup C, Mangrum JC. Prognostic factors in recovered and deteriorated schizophrenics. Am J Psychiatry 1966;122:111621. Crossref

9. Emsley R, Oosthuizen PP, Kidd M, Koen L, Niehaus DJ, Turner HJ. Remission in first-episode psychosis: predictor variables and symptom improvement patterns. J Clin Psychiatry 2006;67:1707-12. Crossref

10. Torgalsbøen AK, Fu S, Czajkowski N. Resilience trajectories to full recovery in first-episode schizophrenia. Eur Psychiatry 2018;52:5460. Crossref

11. Andreasen NC, Carpenter WT Jr, Kane JM, Lasser RA, Marder SR, Weinberger DR. Remission in schizophrenia: proposed criteria and rationale for consensus. Am J Psychiatry 2005;162:441-9. Crossref

12. Liberman RP, Kopelowicz A, Venture J, Gutkind D. Operational criteria and factors related to recovery from schizophrenia. Int Rev Psychiatry 2002;14:256-72. Crossref

13. Park SA, Sung KM. The effects on helplessness and recovery of an empowerment program for hospitalized persons with schizophrenia. Perspect Psychiatr Care 2013;49:110-7. Crossref

14. Jana AK, Ram D, Praharaj SK. Empowerment and its associations in schizophrenia: a cross-sectional study. Community Ment Health J 2014;50:697-701. Crossref

15. World Health Organization. The ICD-10 Classification of Mental and Behavioural Disorders Diagnostic Criteria for Research. 1993.

16. Kay SR, Fiszbein A, Opler LA. The positive and negative syndrome scale (PANSS) for schizophrenia. Schizophr Bull 1987;13:26176. Crossref

17. Patterson DA, Lee MS. Field trial of the Global Assessment of Functioning Scale--Modified. Am J Psychiatry 1995;152:13868. Crossref 
18. van Mastrigt S, Addington J. Assessment of premorbid function in firstepisode schizophrenia: modifications to the Premorbid Adjustment Scale. J Psychiatry Neurosci 2002;27:92-101.

19. Wallace CJ, Liberman RP, Tauber R, Wallace J. The independent living skills survey: a comprehensive measure of the community functioning of severely and persistently mentally ill individuals. Schizophr Bull 2000;26:631-58. Crossref

20. Hogan TP, Awad AG, Eastwood R. A self-report scale predictive of drug compliance in schizophrenics: reliability and discriminative validity. Psychol Med 1983;13:177-83. Crossref

21. Lingjaerde O, Ahlfors UG, Bech P, Dencker SJ, Elgen K. The UKU side effect rating scale. A new comprehensive rating scale for psychotropic drugs and a cross-sectional study of side effects in neuroleptic-treated patients. Acta Psychiatr Scand Suppl 1987;334:1-100. Crossref

22. Singh G, Kaur D, Kaur H. Presumptive Stressful Life Event Scale. Agra: National Psychological Corporation; 1983.

23. Holmes TH, Rahe RH. The Social Readjustment Rating Scale. J Psychosom Res 1967;11:213-8. Crossref

24. Nehra R, Kulhara P, Verma S. Manual for PGI Social Support Questionnaire. Varanasi: Rupa Psychological Centre; 1998.

25. Sarason IG, Levine HM, Basham RB, Sarason BR. Assessing social support: the social support questionnaire. J Pers Soc Psychol 1983;44:127-39. Crossref

26. Sethi BB, Chaturvedi PK, Trivedi JK, Saxena NK. Attitude of family and outcome in schizophrenia. Indian J Soc Psychiatry 1985;1:186-93.

27. Rogers ES, Chamberlin J, Ellison ML, Crean T. A consumerconstructed scale to measure empowerment among users of mental health services. Psychiatr Serv 1997;48:1042-7. Crossref

28. van Os J, Burns T, Cavallaro R, Leucht S, Peuskens J, Helldin L, et al. Standardized remission criteria in schizophrenia. Acta Psychiatr Scand 2006;113:91-5. Crossref

29. Marchesi C, Affaticati A, Monici A, De Panfilis C, Ossola P, Tonna M. Predictors of symptomatic remission in patients with first-episode schizophrenia: a 16 years follow-up study. Compr Psychiatry 2014;55:778-84. Crossref

30. Gaebel W, Riesbeck M, Wölwer W, Klimke A, Eickhoff M, von Wilmsdorff $\mathrm{M}$, et al. Rates and predictors of remission in first-episode schizophrenia within 1 year of antipsychotic maintenance treatment. Results of a randomized controlled trial within the German Research Network on Schizophrenia. Schizophr Res 2014;152:478-86. Crossref

31. Brugha TS. Social Support and Psychiatric Disorder: Overview of Evidence. In: Brugha TS, editor. Social Support and Psychiatric
Disorder Research Findings and Guidelines for Clinical Practice. Cambridge University Press; 1995: 1-40. Crossref

32. Champion L. A Developmental Perspective on Social Support. In: Brugha TS, editor. Social Support and Psychiatric Disorder Research Findings and Guidelines for Clinical Practice. Cambridge University Press; 1995: 41-95. Crossref

33. Rudnick A, Kravetz S. The relation of social support-seeking to quality of life in schizophrenia. J Nerv Ment Dis 2001;189:258-62. Crossref

34. Guedes de Pinho LM, Pereira AMS, Chaves CMCB. Quality of life in schizophrenic patients: the influence of sociodemographic and clinical characteristics and satisfaction with social support. Trends Psychiatry Psychother 2018;40:202-9. Crossref

35. Rosen K, Garety P. Predicting recovery from schizophrenia: a retrospective comparison of characteristics at onset of people with single and multiple episodes. Schizophr Bull 2005;31:735-50. Crossref

36. Guada J, Hoe M, Floyd R, Barbour J, Brekke JS. How family factors impact psychosocial functioning for African American consumers with schizophrenia. Community Ment Health J 2012;48:45-55. Crossref

37. Thonse U, Behere RV, Praharaj SK, Sharma PSVN. Facial emotion recognition, socio-occupational functioning and expressed emotions in schizophrenia versus bipolar disorder. Psychiatry Res 2018;264:35460. Crossref

38. Cechnicki A, Bielańska A, Hanuszkiewicz I, Daren A. The predictive validity of expressed emotions (EE) in schizophrenia. A 20-year prospective study. J Psychiatr Res 2013;47:208-14. Crossref

39. Bachmann S, Bottmer C, Schroder J. One-year outcome and its prediction in first-episode schizophrenia--a naturalistic study. Psychopathology 2008;41:115-23. Crossref

40. Whitty P, Clarke M, McTigue O, Browne S, Kamali M, Kinsella A, et al. Predictors of outcome in first-episode schizophrenia over the first 4 years of illness. Psychol Med 2008;38:1141-6. Crossref

41. Penttilä M, Jääskeläinen E, Hirvonen N, Isohanni M, Miettunen J. Duration of untreated psychosis as predictor of long-term outcome in schizophrenia: systematic review and meta-analysis. Br J Psychiatry 2014;205:88-94. Crossref

42. Díaz-Caneja CM, Pina-Camacho L, Rodríguez-Quiroga A, Fraguas D, Parellada M,Arango C. Predictors of outcome in early-onset psychosis: a systematic review. NPJ Schizophr 2015;1:14005. Crossref

43. Aikawa S, Kobayashi H, Nemoto T, Matsuo S, Wada Y, Mamiya N, et al. Social anxiety and risk factors in patients with schizophrenia: relationship with duration of untreated psychosis. Psychiatry Res 2018;263:94-100. Crossref 